\title{
Differential gene expression in mouse spermatogonial stem cells and embryonic stem cells
}

\author{
YINSHAN BAI ${ }^{1,2}$, MEIYING FENG ${ }^{2}$, SHANSHAN LIU ${ }^{1}$, HENGXI WEI $^{2}$, LI LI $^{2}$, XIANWEI ZHANG ${ }^{2}$, \\ CHAO SHEN $^{2}$, SHOUQUAN ZHANG ${ }^{2}$ and NINGFANG MA ${ }^{1}$ \\ ${ }^{1}$ Department of Histology and Embryology, School of Basic Sciences, Guangzhou Medical University, \\ Guangzhou, Guangdong 511436; ${ }^{2}$ National Engineering Research Center for Breeding Swine Industry, \\ Guangdong Provincial Key Laboratory of Agro-Animal Genomics and Molecular Breeding, \\ College of Animal Science, South China Agricultural University, Guangzhou, Guangdong 510642, P.R. China
}

Received May 31, 2015; Accepted June 17, 2016

DOI: $10.3892 / \mathrm{ijmm} .2016 .2658$

\begin{abstract}
Mouse spermatogonial stem cells (mSSCs) may be reprogrammed to become pluripotent stem cells under in vitro culture conditions, due to epigenetic modifications, which are

Correspondence to: Professor Ningfang Ma, Department of Histology and Embryology, School of Basic Sciences, Guangzhou Medical University, Xinzao, Panyu, Guangzhou, Guangdong 511436, P.R. China E-mail: nfma@gzhmu.edu.cn

Professor Shouquan Zhang, National Engineering Research Center for Breeding Swine Industry, Guangdong Provincial Key Laboratory of Agro-Animal Genomics and Molecular Breeding, College of Animal Science, South China Agricultural University, 483 Wushan Road, Tianhe, Guangzhou, Guangdong 510642, P.R. China

E-mail: sqzhang@scau.edu.cn
\end{abstract}

Abbreviations: Dnmt1, DNA methyltransferase 1; Dmrt1, doublesex and mab-3 related transcription factor 1; Dot 1l, disruptor of telomeric silencing 1-like; Dppa2, developmental pluripotency associated 2; $E s r r b$, estrogen-related receptor b; iPSCs, induced pluripotent stem cells; $K d m 2 b$, lysine (K)-specific demethylase 2b; Klf2, Krüppel-like factor 2; Klf4, Krüppel-like factor 4; Lin28, Lin-28 homolog A; MACS, magnetic-activated cell sorting; Max, Myc associated factor x; MEF, mouse embryonic fibroblast; mESCs, mouse embryonic stem cells; mSSCs (f), freshly isolated mouse spermatogonial stem cells; mSSCs (1), long-term propagated mouse spermatogonial stem cells; $N r 5 a 2$, nuclear receptor subfamily 5, group A, member 2; Oct4, octamer-binding transcription factor 4; Parp1, poly[ADP-ribose] polymerase 1; Prdm14, PR domain containing 14; Prmt5, protein Arg N-methyltransferase 5; RS, round spermatid; Sox2, Sry (sex determining region Y)-box 2; SSCs, spermatogonial stem cells; Tbx3, T-box 3; Tert, telomerase reverse transcriptase; Tet1, ten-eleven translocation methylcytosine dioxygenase 1 ; Tet 2 , ten-eleven translocation methylcytosine dioxygenase 2 ; Tet 3 , ten-eleven translocation methylcytosine dioxygenase $3 ; \operatorname{Trfl} 1$, telomeric repeat binding factor 1 ; $U t f 1$, undifferentiated embryonic cell transcription factor 1 ; Zscan $4 c$, zinc finger and SCAN domain containing $4 \mathrm{c}$.

Key words: mouse spermatogonial stem cells, mouse embryonic stem cells, transcription factors, epigenetic factors, gene expression, reprogramming closely associated with the expression of transcription-factors and epigenetic factors. Thus, this study was conducted to compare the gene expression of transcription factors and epigenetic factors in mSSCs and mouse embryonic stem cells (mESCs). Firstly, the freshly isolated mSSCs [mSSCs (f)] were enriched by magnetic-activated cell sorting with Thy1.2 (CD90.2) microbeads, and the typical morphological characteristics were maintained under in vitro culture conditions for over 5 months to form long-term propagated mSSCs [mSSCs (1)]. These mSSCs (1) expressed pluripotency-associated genes and were induced to differentiate into sperm. Our findings indicated that the mSSCs (1) expressed high levels of the transcription factors, Lin28 and Prmt5, and the epigenetic factors, Tet3, Parpl, Max, Tert and Trf1, in comparison with the mESCs, with the levels of Prmt5, Tet3, Parpl and Tert significantly higher than those in the mESCs. There was no significant difference in $\mathrm{Kdm} 2 \mathrm{~b}$ expression between mSSCs (l) and mESCs. Furthermore, the gene expression of $\mathrm{N}-\mathrm{Myc}, \mathrm{Dppa2}, \mathrm{Tbx} 3, \mathrm{Nr} 5 \mathrm{a} 2$, Prmt5, Tet3, Parp1, Max, Tert and Trfl in the mSSCs (1) was markedly higher in comparison to that in the mSSCs (f). Collectively, our results suggest that the $\mathrm{mSSCs}$ and the mESCs displayed differential gene expression profiles, and the mSSCs possessed the potential to acquire pluripotency based on the high expression of transcription factors and epigenetic factors. These data may provide novel insights into the reprogramming mechanism of mSSCs.

\section{Introduction}

Spermatogonial stem cells (SSCs) are unipotent germ cells which have been demonstrated to express many pluripotency-associated genes as well as alkaline phosphatase (AP) activity as they are pluripotent stem cells (PSCs) $(1,2)$. They also possess the potential ability to reacquire pluripotency due to spontaneous epigenetic reprogramming (3). Epigenetic mechanisms are closely associated with the induction and the maintenance of pluripotency (4). Previous findings have revealed the complex connection between epigenetic modification factors and pluripotent transcription factors, both of which control gene expression directly linked to pluripotency and reprogramming (5). It has been demonstrated that the 
generation of induced (i)PSCs relies on the exogenous expression of transcription factors (such as Oct4, Sox2, N-Myc and Klf4), which is an inefficient and random reprogramming process (6). However, epigenetic factors have been shown to provide a more powerful means of improving reprogramming efficiency (7). In fact, the molecular mechanism responsible for the in vitro reprogramming of SSCs may provide insight into the epigenetic reprogramming of iPSCs (5).

Although previous experiments have investigated the differences in transcript and proteomic profiles between mouse $(\mathrm{m}) \mathrm{SSC}$ and mouse embryonic stem cells (mESCs) $(8,9)$, differences in the expression of crucial transcription factors and epigenetic factors remain unclear. A recent study has indicated that the loss of Dmrt1, Dnmt1 and tumor protein (Tp)53 expression, and the overexpression of Oct4 increased the rate of $\mathrm{mSSC}$ reprogramming (10). However, the mechanism of SSC reprogramming to PSCs remains unknown, particularly due to the difficulty of tracing orchestrated epigenetic changes during the very low-efficiency reprogramming process (10). As a result, it becomes increasingly important to determine the differential gene expression of pluripotent factors and epigenetic factors in mSSCs and mESCs in order to elucidate the mechanism of $\mathrm{mSSC}$ reprogramming. Thus, we examined the relative mRNA expression of ESC-associated transcription factors and epigenetic factors in freshly isolated mSSCs [mSSCs (f)] and long-term propagated mSSCs [mSSC (1)] versus mESCs.

\section{Materials and methods}

Isolation of $\operatorname{mSSCs}(f)$. The mSSCs were isolated from 6-day-old imprinting control region (ICR) male mouse testes at our laboratory by two-step enzyme digestion and magnetic-activated cell sorting (MACS) with CD90.2 microbeads (Miltenyi Biotec, Bergisch Gladbach, Germany) as previously described (11). The experiment was repeated $>3$ times and 30 mice were used each time. The mice were sacrificed by decapitation and the testes were removed for the isolation of mSSCs. All procedures were performed in accordance with the animal care guidelines of the Institutional Animal Care and Use Committee of Guangzhou Medical University (Guangdong, China) and were conducted in accordance with the National Research Council Guide for the Care and Use of Laboratory Animals.

Culture of $m S S C s$ and $m E S C s$. The purified mSSCs (f) were cultured on mouse embryonic fibroblast (MEF) feeder cells treated with mitomycin C (Sigma, St. Louis, MO, USA). The cells were cultured in StemPro-34 SFM, a serum-free medium (Invitrogen, Carlsbad, CA, USA) supplemented with $20 \mathrm{ng} / \mathrm{ml}$ recombinant rat glial cell line-derived neurotrophic factor, $10 \mathrm{ng} / \mathrm{ml}$ recombinant human basic fibroblast growth factor (both from PeproTech, Rocky Hill, NJ, USA), $10 \mathrm{ng} / \mathrm{ml}$ mouse epidermal growth factor (Prospec-Tany TechnoGene, Ltd., East Brunswick, NJ, USA), 1,000 U/ml recombinant mouse leukemia inhibitory factor (LIF; Millipore, Billerica, MA, USA), $20 \mathrm{ng} / \mathrm{ml}$ platelet-derived growth factor-BB (PeproTech), $1 \mathrm{mmol} / 1$ glutamine, $1 \mathrm{X}$ insulin-transferrinselenium (ITS), and 1X B27 supplements (all from Gibco, Grand Island, NY, USA). The mSSCs (f) $(5 \times 105 / \mathrm{ml})$ cultured in a $25 \mathrm{~cm}^{2}$ flask under these conditions were passaged every 7 days and the culture medium was changed every 2 days. After culturing for 4 weeks, the mSSCs (f) were capable of stably proliferating in vitro as mSSCs (1). Trypsin-EDTA (0.25\% Invitrogen) and Accutase ( $1 \mathrm{mg} / \mathrm{ml}$, Sigma) were used to split mSSCs clusters away from MEF feeder cells. To maintain the adherent state of MEF feeder cells, the process of digestion was controlled within no more than 1 min, observed under a light microscope and stopped using the completed culture medium. The mSSC clusters were transferred to a centrifuge tube and centrifuged under $69 \mathrm{x} \mathrm{g}$ at $4^{\circ} \mathrm{C}, 3 \mathrm{~min}$ after washing with phosphate-buffered saline (PBS).

The mESC (R1) cell line was kindly donated by Dr Shaorong Gao at the School of Life Sciences and Technology at Tongji University (Shanghai, China). The in vitro culture and characterization of mESCs (R1) and the induced differentiation of mSSCs into round spermatids (RSs) were performed as previously described $(11,12)$. Briefly, the mESC (R1) cell line was cultured in DMEM (Gibco) supplemented with $1 \mathrm{mmol} / 1$ glutamine (Gibco), 100X nucleotide (Millipore), 55 $\mu \mathrm{M} \beta-\mathrm{ME}$ (Gibco), $15 \%$ fetal bovine serum (FBS; Gibco) and $1,000 \mathrm{U} / \mathrm{ml} \mathrm{LIF}$ (Millipore), on the MEF feeder cells. For the induction of sperm differentiation, the $\mathrm{mSSCs}$ were cultured in DMEM (Gibco) supplemented with 10\% FBS (Gibco), 500 $\mathrm{ng} / \mathrm{ml}$ follicle-stimulating hormone (Sigma), $5 \mu \mathrm{M}$ vitamin A (Sigma), $0.1 \mathrm{mM}$ testosterone (Sigma), 100X ITS (Gibco), 1 mmol/l glutamine (Gibco), 100X sodium pyruvate (Gibco), and 100X nonessential amino acid (NEAA; Gibco) on mouse testicular fibroblast feeder cells.

AP staining of $m S S C s$. The $\mathrm{mSSC}$ clusters were fixed in $4 \%$ paraformaldehyde at room temperature for $20 \mathrm{~min}$ and then washed three times with PBS for $15 \mathrm{~min}$. The detector reagents from the AP detection kit (Dingguo Changsheng Biotechnology Co., Ltd., Beijing, China) were then added and the samples were incubated at room temperature (in the dark) for $15 \mathrm{~min}$. The reaction was terminated by performing three PBS washes. Images were captured using a light microscope (IX71 model with TH4-200 accessories; Olympus, Tokyo, Japan).

Immunohistochemical analysis. The mouse testes were fixed in $4 \%$ paraformaldehyde for $24 \mathrm{~h}$, embedded in paraffin, and processed for immunohistochemical analysis. Briefly, 5- $\mu \mathrm{m}$ section slides were dewaxed in xylene and rehydrated using a series of graded alcohols. Immunostaining was performed by incubating the slides with the mouse monoclonal anti-promyelocytic leukaemia zinc finger (PLZF) antibody (sc-28319; 1:100) overnight at $4^{\circ} \mathrm{C}$, followed by incubation with goat anti-mouse IgG-HRP (sc-2005; 1:200) (both from Santa Cruz Biotechnology, Inc., Santa Cruz, CA, USA) at $37^{\circ} \mathrm{C}$ for $1 \mathrm{~h}$. The sections of the mouse testes were counterstained with hematoxylin after diaminobenzidine staining (both from Dingguo Changsheng Biotechnology Co. Ltd., Beijing, China) and examined under a light microscope (Olympus).

Immunofluorescence. The mSSC clusters were fixed with $4 \%$ paraformaldehyde for $30 \mathrm{~min}$, washed three times with 
PBS, and blocked in 1\% BSA (Sigma) for $30 \mathrm{~min}$. The cells were incubated with a mouse monoclonal anti-GFR $\alpha 1$ antibody (sc-271546; 1:200; Santa Cruz Biotechnology, Inc.) and an anti-PLZF mouse IgG antibody (sc-28319; 1:200; Santa Cruz Biotechnology, Inc.) at $4^{\circ} \mathrm{C}$ overnight and washed three times in PBS. The secondary antibody, Alexa Fluor 568-labeled goat anti-mouse IgG (1:100; Invitrogen) was added and incubated for $1 \mathrm{~h}$ at $37^{\circ} \mathrm{C}$ in the dark. The cell nuclei were stained with $10 \mu \mathrm{g} / \mathrm{ml}$ Hoechst 33342 (Molecular Probes, Eugene, OR, USA). The samples were observed under a fluorescent microscope (IX71 with U-RFL-T accessories; Olympus).

Flow cytometric analysis. The mSSC clusters were digested with Accutase (Stem Cell Technologies, Inc., Vancouver, BC, Canada) and the collected cells were fixed in $4 \%$ paraformaldehyde for $20 \mathrm{~min}$ followed by three washes with PBS. The cells were then stained with mouse monoclonal anti-CD90.2FITC (Miltenyi Biotec) for $30 \mathrm{~min}$ at $4^{\circ} \mathrm{C}$ in the dark and detected by flow cytometry (FACSCalibur; BD Biosciences, Franklin Lakes, NJ, USA).

RNA extraction, cDNA synthesis, and reverse transcriptionquantitative polymerase chain reaction ( $R T-q P C R)$. Total RNA was extracted from mSSCs (f), mSSCs (l), and mESCs using an RNeasy mini kit (Qiagen, Inc., Valencia, CA, USA) according to the manufacturer's instructions. RNA was transcribed to cDNA using a cDNA synthesis kit (Takara, Otsu, Japan) with oligo-dT primers. The primer sequences used in this study are listed in Tables I and II. Relative mRNA expression analyses were run in triplicate for each sample using a Power SYBR-Green Realtime PCR kit (Toyobo Co., Ltd., Osaka, Japan) on a qPCR machine (Illumina, Inc., San Diego, CA, USA). $\beta$-actin was used as an internal control. The relative mRNA abundance of target genes was expressed as $2^{-\Delta \Delta C t}$.

Western blot analysis. Proteins were extracted from mSSCs (1) and mESCs using RIPA lysis buffer (Beyotime, Shanghai, China) containing $1 \%$ protease inhibitor cocktail (Roche, Mannheim, Germany). The lysed samples were centrifuged at $4^{\circ} \mathrm{C}, 10,000 \mathrm{x} \mathrm{g}$ for $15 \mathrm{~min}$ to obtain the supernatants. Protein concentrations in the supernatants were determined using the BCA protein assay kit (Bio-Rad, Hercules, CA, USA). The supernatant proteins were denatured, separated by SDS-PAGE, and transferred to nitrocellulose membranes (Bio-Rad). The membranes were blocked with 5\% non-fat dry milk powder in $1 \mathrm{X}$ PBS containing $0.1 \%$ Tween-20 (TBST) for $1 \mathrm{~h}$ at room temperature. The blots were incubated with primary antibodies [rabbit anti-mouse PRMT5 (ab2538; 1:200; MultiSciences Biotech Co., Ltd., Hangzhou, China); rabbit anti-mouse LIN28 homolog A (LIN28) (sc-67266; 1:200); rabbit anti-mouse $\beta$-actin (sc-130656; $1: 1,000)$ in TBST with $5 \%$ non-fat milk overnight at $4^{\circ} \mathrm{C}$ with gentle shaking, followed by incubation with peroxidase-conjugated secondary antibody (goat anti-rabbit IgG-HRP; sc-2030; 1:1000) (all from Santa Cruz Biotechnology, Inc.) in TBST with 5\% non-fat milk for $2 \mathrm{~h}$ at room temperature. Chemiluminescence signals were detected using SuperSignal West Dura HRP detection kits (Pierce, Rockford, IL, USA). The images were captured using a ChemiDoc XRS system equipped with Quantity One software (Bio-Rad).
DNA methylation analysis. Genomic DNA was extracted from mSSCs (1) and mESCs using a Genomic DNA kit (Tiangen Biotechnology, Beijing, China) and treated with an EZ DNA Methylation-Gold kit (Zymo Research, Irvine, CA, USA) to deaminate unmethylated cytosines to uracils. The DNA templates were used to amplify differentially methylated regions (DMRs) by specific primers (forward, 5'-TGGTTGTTT TGTAGGATTTGTTAGA-3' and reverse, 5'-AAAAC TTCCCTCTTCCCTCTTAATAT-3'). The amplified products were then purified using a Gel Extraction kit (Omega Bio-Tek, Inc., Norcross, GA, USA), subcloned into pMD ${ }^{\mathrm{TM}} 18-\mathrm{T}$ vectors (Takara) and sequenced by M13R primers.

Statistical analysis. The differences between groups were assessed using ANOVA and Student's t-tests with SPSS v.11 software. The results are presented as the means \pm standard error. A p $<0.05$ was considered to indicate a statistically significant difference.

\section{Results}

Isolation of $\operatorname{mSSCs}(f)$. Immunohistochemical staining of sections of 6-day-old male ICR mouse testes showed that the PLZF-positive mSSCs were localized to the basal membrane of the testicular seminiferous tubules (Fig. 1A). The mSSCs (f), enriched by CD90.2 microbeads, displayed a unified morphological appearance (Fig. 1B) and AP staining activity (Fig. 1C). These mSSCs (f) had a purity of $79.5 \%$, as detected by flow cytometry (Fig. 1D), and immunofluorescence staining confirmed that they expressed the SSC marker, PLZF protein (Fig. 1E-G).

Propagation and characterization of mSSCs (l). The self-renewal capacity of mSSCs (f) was maintained in vitro for $>5$ months [to produce mSSCs (1)] on MEF feeder cells (Fig. 2A and B). The mSSCs (1) displayed AP activity (Fig. 2C) and expressed CD90.2 (Fig. 2D) and GFR $\alpha 1$ (Fig. 2E-G). These colonies of mSSCs (1) were quite different from the colonies of mESCs (Fig. 2H and I). Furthermore, RT-PCR revealed that the mSSCs (l) expressed germline factors (Plzf, Vasa, Dazl, Nanos3 and Stra8), ESC pluripotency factors (Oct4, Sox2, Nanog, Lin28, N-Myc, Klf4 and Tert) and Cldn6 and Pdgfro surface markers, whereas MEFs only expressed N-Myc and Klf4 (Fig. 2J).

Differentiation of $m S S C s(l)$. Our results indicated that mSSCs (1) were capable of differentiating into sperm in vitro. After 7 days of differentiation culture, A-paired (Apr) spermatogonia were observed (Fig. 3A). Subsequently, A-aligned (Aal) spermatogonia of 4- (Aal-4) (Fig. 3B), 8- (Aal-8) (Fig. 3C) and 16-cells (Aal-16) (Fig. 3D) emerged on days 8, 10 and 11, respectively. Next, A1, A2, A3, A4, intermediate (In), and B spermatogonia began to appear from days 12 to 14 (Fig. 3E and F). During this pivotal developmental time frame, differentiated spermatogonia (A2 to B) derived from A1 cells were synthesized in bulk in preparation for meiosis. Round spermatids (RSs) were formed on day 16 (Fig. 3G) after meiosis. These RSs expressed sperm markers (Gsg2 and Acrosin), whereas mESCs did not express either gene (Fig. 3H). 
Table I. Primer sequence, target product size and accession number of target genes for regular PCR.

\begin{tabular}{|c|c|c|c|}
\hline Gene & Primer sequence $\left(5^{\prime} \rightarrow 3^{\prime}\right)$ & Product size $(b p)$ & Accession no. \\
\hline$\beta$-actin & $\begin{array}{l}\text { F: TGCTGTCCCTGTATGCCTCTG } \\
\text { R: TGATGTCACGCACGATTTCC }\end{array}$ & 222 & NM_007393.3 \\
\hline Oct 4 & $\begin{array}{l}\text { F: GGGATGGCATACTGTGGACC } \\
\text { R: CAGAGCAGTGACGGGAACAGA }\end{array}$ & 837 & NM_013633.3 \\
\hline Sox2 & $\begin{array}{l}\text { F: AAACCACCAATCCCATCCAA } \\
\text { R: TTGCCTTAAACAAGACCACGAA }\end{array}$ & 459 & U31967.1 \\
\hline Nanog & $\begin{array}{l}\text { F: CTGATTCTTCTACCAGTCCCAAAC } \\
\text { R: AGATGCGTTCACCAGATAGCC }\end{array}$ & 380 & XM_006506651.1 \\
\hline $\operatorname{Lin} 28$ & $\begin{array}{l}\text { F: CCAAAGGAGACAGGTGCTACAA } \\
\text { R: GGCAGGCTTTCCCTGAGAA }\end{array}$ & 167 & XM_006539317.1 \\
\hline$N-M y c$ & $\begin{array}{l}\text { F: GGTGGGTCGTCGAGTGCTAG } \\
\text { R: AGTGGTTACCGCCTTGTTGTTA }\end{array}$ & 393 & M36277.1 \\
\hline Klf4 & $\begin{array}{l}\text { F: ACTAACCGTTGGCGTGAGGA } \\
\text { R: TGCTAACACTGATGACCGAAGG }\end{array}$ & 625 & ВC010301.1 \\
\hline Tert & $\begin{array}{l}\text { F: AGCATTTCACCCAGCGTCTC } \\
\text { R: TGCTCGATGACAACGGAGTTC }\end{array}$ & 436 & XM_006517210.1 \\
\hline Plzf & $\begin{array}{l}\text { F: ACCCATACTGGCACGGACAT } \\
\text { R: TGTGAACCCTGTAGTGCGTCTC }\end{array}$ & 346 & XM_006510258.1 \\
\hline Vasa & $\begin{array}{l}\text { F: AGCATTCCCATTGTATTAGCAGG } \\
\text { R: CACTTGCCCAACAGCGACA }\end{array}$ & 573 & NM_001145885.1 \\
\hline Dazl & $\begin{array}{l}\text { F: GTTAGGATGGATGAAACCGAAAT } \\
\text { R: CAGATTTAAGCACTGCCCGAC }\end{array}$ & 739 & NM_010021.5 \\
\hline Nanos3 & $\begin{array}{l}\text { F: CGAGTCCCGTGCCATCTATC } \\
\text { R: GGGGCTTCCTGCCACTTT }\end{array}$ & 302 & NM_194059.2 \\
\hline Stra8 & $\begin{array}{l}\text { F: AGGCAACCAACCCAGTGATG } \\
\text { R: TCCTGTTCCTGAATATGAATCTTTGT }\end{array}$ & 156 & XM_006505829.1 \\
\hline Cldn6 & $\begin{array}{l}\text { F: GGCAACAGCATCGTCGTGG } \\
\text { R: GAAGTCCTGGATGATAGAGTGGGC }\end{array}$ & 333 & NM_018777.4 \\
\hline Pdgfr $\alpha$ & $\begin{array}{l}\text { F: GTTCAAGACCAGCGAGTTTAATGT } \\
\text { R: GCCAAAGGTGGGCTCAATC }\end{array}$ & 376 & NM_011058.2 \\
\hline Gsg2 & $\begin{array}{l}\text { F: CTTTAGTGATTGCCTTTCCACG } \\
\text { R: GTGGGAATGGTGCTCGTTTT }\end{array}$ & 612 & D87326.1 \\
\hline Acrosin & $\begin{array}{l}\text { F: TCTTGGCAGTGTCCGTGGTT } \\
\text { R: TGTTTCTTCCATATTCGATTTCTTGT }\end{array}$ & 309 & D00754.1 \\
\hline
\end{tabular}

F, forward primer; $R$, reverse primer.

Relative $m R N A$ expression of transcription factors in $\mathrm{mSSCS}$. The relative mRNA expression of transcription factors (Oct4, Sox2, Nanog, N-Myc, Klf4, Esrrb, Utf1, Dppa2, Tbx3, Nr5a2, $\operatorname{Prdm} 14$ and $K l f 2$ ) in both types of mSSC was significantly lower than those in the mESCs (Fig. 4A). For example, the expression of Oct4, Sox 2 and Nanog in the mESCs was significantly higher than in the mSSCs (1). Notably, the expression level of Prmt5 and Lin28 was significantly higher in the mSSCs (1) versus the mESCs. Western blot analysis also confirmed that the mSSCs (l) and the mESCs expressed LIN28 and PRMT5 proteins (Fig. 4C). The mRNA expression of Dmrtl in both the mSSC types was higher compared with that in the mESCs (Fig. 4A). Additionally, our results indicated that the expression of $N-M y c, D p p a 2, T b x 3, N r 5 a 2$ and Prmt5 in the mSSCs (l) was markedly upregulated in comparison with the mSSCs (f) (Fig. 4A). Confirmation of the qPCR products of the transcription factors was also demonstrated (Fig. 4B).

Relative mRNA expression of epigenetic factors in mSSCs. Epigenetic factors critical for promoting pluripotency and 
Table II. Primer sequence, target product size and accession number of target genes for RT-qPCR.

\begin{tabular}{|c|c|c|c|}
\hline Gene & Primer sequence $\left(5^{\prime} \rightarrow 3^{\prime}\right)$ & Product size (bp) & Accession no. \\
\hline$\beta$-actin & $\begin{array}{l}\text { F: TGCTGTCCCTGTATGCCTCTG } \\
\text { R: TGATGTCACGCACGATTTCC }\end{array}$ & 222 & NM_007393.3 \\
\hline Oct4 & $\begin{array}{l}\text { F: GTGTTCAGCCAGACCACCATC } \\
\text { R: CATTGTTGTCGGCTTCCTCC }\end{array}$ & 112 & NM_013633.3 \\
\hline Sox 2 & $\begin{array}{l}\text { F: CAAGGAAGGAGTTTATTCGGATTT } \\
\text { R: ATCAACCTGCATGGGCATTT }\end{array}$ & 178 & U31967.1 \\
\hline Nanog & $\begin{array}{l}\text { F: CTGATTCTTCTACCAGTCCCAAAC } \\
\text { R: GCTTCTGAAACCTGTCCTTGAGT }\end{array}$ & 156 & XM_006506651.1 \\
\hline $\operatorname{Lin} 28$ & $\begin{array}{l}\text { F: CCAAAGGAGACAGGTGCTACAA } \\
\text { R: GGCAGGCTTTCCCTGAGAA }\end{array}$ & 167 & XM_006539317.1 \\
\hline$N-M y c$ & $\begin{array}{l}\text { F: TCCTCTAACAACAAGGCGGTAA } \\
\text { R: TGTGCTGCTGATGGATGGG }\end{array}$ & 130 & M36277.1 \\
\hline Klf4 & $\begin{array}{l}\text { F: ACTAACCGTTGGCGTGAGGA } \\
\text { R: CGTTGAACTCCTCGGTCTCC }\end{array}$ & 175 & ВC010301.1 \\
\hline Esrrb & $\begin{array}{l}\text { F: CATGAAATGCCTCAAAGTGGG } \\
\text { R: TCCTGCTCAACCCCTAGTAGATT }\end{array}$ & 186 & NM_011934.4 \\
\hline Utfl & $\begin{array}{l}\text { F: TCCTCTTACGAGCACCGACAC } \\
\text { R: GAGCAACCTGCGGGGAA }\end{array}$ & 146 & NM_009482.2 \\
\hline Dppa2 & $\begin{array}{l}\text { F: GAGGAGCCAAACACAGACTACG } \\
\text { R: CGGAGGACAGGTGCTTGGT }\end{array}$ & 138 & AF490346 \\
\hline$T b x 3$ & $\begin{array}{l}\text { F: GGAACCCGAAGAAGACGTAGAA } \\
\text { R: CTTTTTATCCAGTCCAGAGCACC }\end{array}$ & 160 & NM_011535.3 \\
\hline$N r 5 a 2$ & $\begin{array}{l}\text { F: TCCCACACCTGATACTGGAACTT } \\
\text { R: GCTTTTCTTGCCTGTTTCGG }\end{array}$ & 114 & NM_030676.3 \\
\hline $\operatorname{Prdm} 14$ & $\begin{array}{l}\text { F: GAGTGAGATTTGGACCCTTTCG } \\
\text { R: ACCGAGCACAGTTGACATAGGAC }\end{array}$ & 165 & NM_001081209 \\
\hline Klf 2 & $\begin{array}{l}\text { F: CCCAGGAAAGAAGACAGGAGTCT } \\
\text { R: ACTCAAAGGCATTTCTCACAAGG }\end{array}$ & 122 & NM_008452.2 \\
\hline Prmt5 & $\begin{array}{l}\text { F: CCTTTGCCGACAACGAGC } \\
\text { R: AAACTGTGCCTCAGGATCGC }\end{array}$ & 179 & NM_013768.3 \\
\hline Dmrtl & $\begin{array}{l}\text { F: GGAGCGACAGCGGGTGA } \\
\text { R: CGGGTTGCTGGCATTATTCT }\end{array}$ & 142 & AF202778.1 \\
\hline Tet 1 & $\begin{array}{l}\text { F: CCTATCTTCCTTCCTAAGCCTCC } \\
\text { R: TCAGGGTTTGGTGGGAGTTG }\end{array}$ & 164 & NM_001253857.1 \\
\hline Tet 2 & $\begin{array}{l}\text { F: AATGGAAGCCCGTTAGCAGA } \\
\text { R: GCACCTGGAATACCCTCTGTCT }\end{array}$ & 150 & XM_006501281.1 \\
\hline Tet3 & $\begin{array}{l}\text { F: GCTCGTCTGGAAGATGCCC } \\
\text { R: CTCACGACTCATCTCACGGTTG }\end{array}$ & 120 & XM_006505773.1 \\
\hline Parpl & $\begin{array}{l}\text { F: CGTCAACTACGAGAAACTCAAAACT } \\
\text { R: AGGTCATAGGCGTTGTGCG }\end{array}$ & 120 & NM_007415.2 \\
\hline Dnmt1 & $\begin{array}{l}\text { F: AGTCGGACAGTGACACCCTTTC } \\
\text { R: GGTTTCCGTTTAGTGGGGC }\end{array}$ & 118 & NM_001199431.1 \\
\hline$K d m 2 b$ & $\begin{array}{l}\text { F: ACTCACCTTACCGAATTTGAACTG } \\
\text { R: ACGTGCTCTTTCAGTACATTCTTTAC }\end{array}$ & 149 & NM_001003953.1 \\
\hline Dotll & $\begin{array}{l}\text { F: CTGGCAAGCCTGTCTCCTACTAT } \\
\text { R: CGTGGTCGCATTGCTCTTG }\end{array}$ & 149 & NM_199322.1 \\
\hline
\end{tabular}


Table II. Continued.

\begin{tabular}{|c|c|c|c|}
\hline Gene & Primer sequence $\left(5^{\prime} \rightarrow 3^{\prime}\right)$ & Product size (bp) & Accession no. \\
\hline $\operatorname{Max}$ & $\begin{array}{l}\text { F: CTCTACACCAACGCCAAGGG } \\
\text { R: CAGAAGGAGGATGCGACGAG }\end{array}$ & 178 & NM_001146176.1 \\
\hline Tert & $\begin{array}{l}\text { F: TGCTGGACACTCAGACTTTGGA } \\
\text { R: TTCAACCGCAAGACCGACA }\end{array}$ & 102 & XM_006517210.1 \\
\hline $\operatorname{Trfl}$ & $\begin{array}{l}\text { F: AAGAACGCCTTATCGCAGTTAA } \\
\text { R: TCCACTGGTTCTTCGGTTCC }\end{array}$ & 120 & NM_009352.3 \\
\hline Zscan $4 c$ & $\begin{array}{l}\text { F: GCAAATGTTGGTGAAAGCTGTAGT } \\
\text { R: TAGTCGGAGCACTCGGGAAG }\end{array}$ & 175 & NM_001013765.2 \\
\hline
\end{tabular}

$\mathrm{F}$, forward primer; $\mathrm{R}$, reverse primer.
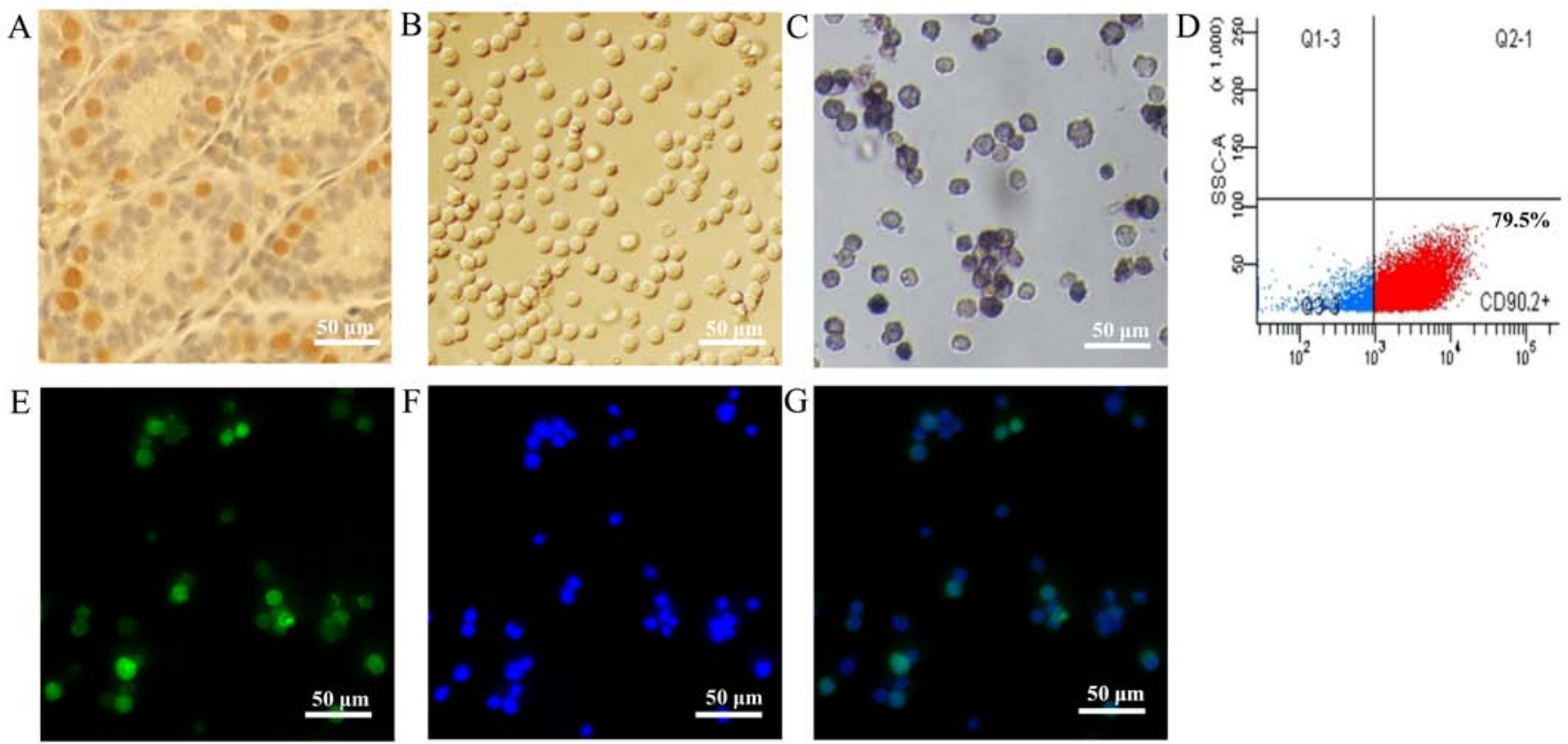

Figure 1. Isolation and identification of mouse spermatogonial stem cells (mSSCs). Representative images of (A) promyelocytic leukaemia zinc finger (PLZF) immunohistochemical staining performed on 6-day-old ICR mouse testes, (B) CD90.2-positive mSSCs enriched by the magnetic-activated cell sorting (MACS) system and (C) freshly isolated mSSCs [mSSCs (f)] exhibiting alkaline phosphatase (AP) staining activity. (D) Flow cytometric analysis of mSSCs (f) performed using the CD90.2 antibody. Representative images of (E) immunofluorescence staining of PLZF in mSSCs (f), and (F) Hochest 33342 -stained cell nuclei in mSSCs (f). (G) Merged images of (E and F).

reprogramming were investigated (Fig. 5), including the genes responsible for genomic methylation regulation (Tet1, Tet2, Tet3, Parpl and Dnmt1, histone modification $(K d m 2 b$, Dotll and Max), and telomere maintenance (Tert, Trfl and Zscan 4c). The results of RT-qPCR revealed that the mSSCs and the mESCs exhibited different expression levels of these factors (Fig. 5A). Tet1, Tet2 and Zscan4c were abundantly expressed in the mESCs but not in the mSSCs (1), whereas the levels of Tet3, Parp1,Dnmt1, Dotll and Tert were significantly higher in the mSSCs than in the mESCs (Fig. 5A). To further examine the possible association between the low expression of Tet2 and DNA methylation, we determined the DNA methylation state of the Tet 2 promoter. However, the Tet 2 promoter in the mSSCs (1) did not show a high DNA methylation level by bisulfite sequencing PCR analysis (Fig. 5C). Furthermore, $K d m 2 b$ expression was significantly higher in the mSSCs (f) than in the mESCs and the mSSCs (1) (Fig. 5A). All three cell types exhibited different expression levels of Max (Fig. 5A). Lower levels of $\operatorname{Trfl} 1$ were expressed in the mESCs than in the mSSCs (1) (Fig. 5A). Confirmation of the qPCR products of the epigenetic factors was also demonstrated (Fig. 5B).

\section{Discussion}

It has been previously demonstrated that the membrane protein CD90.2 was extensively expressed on the surface 
A
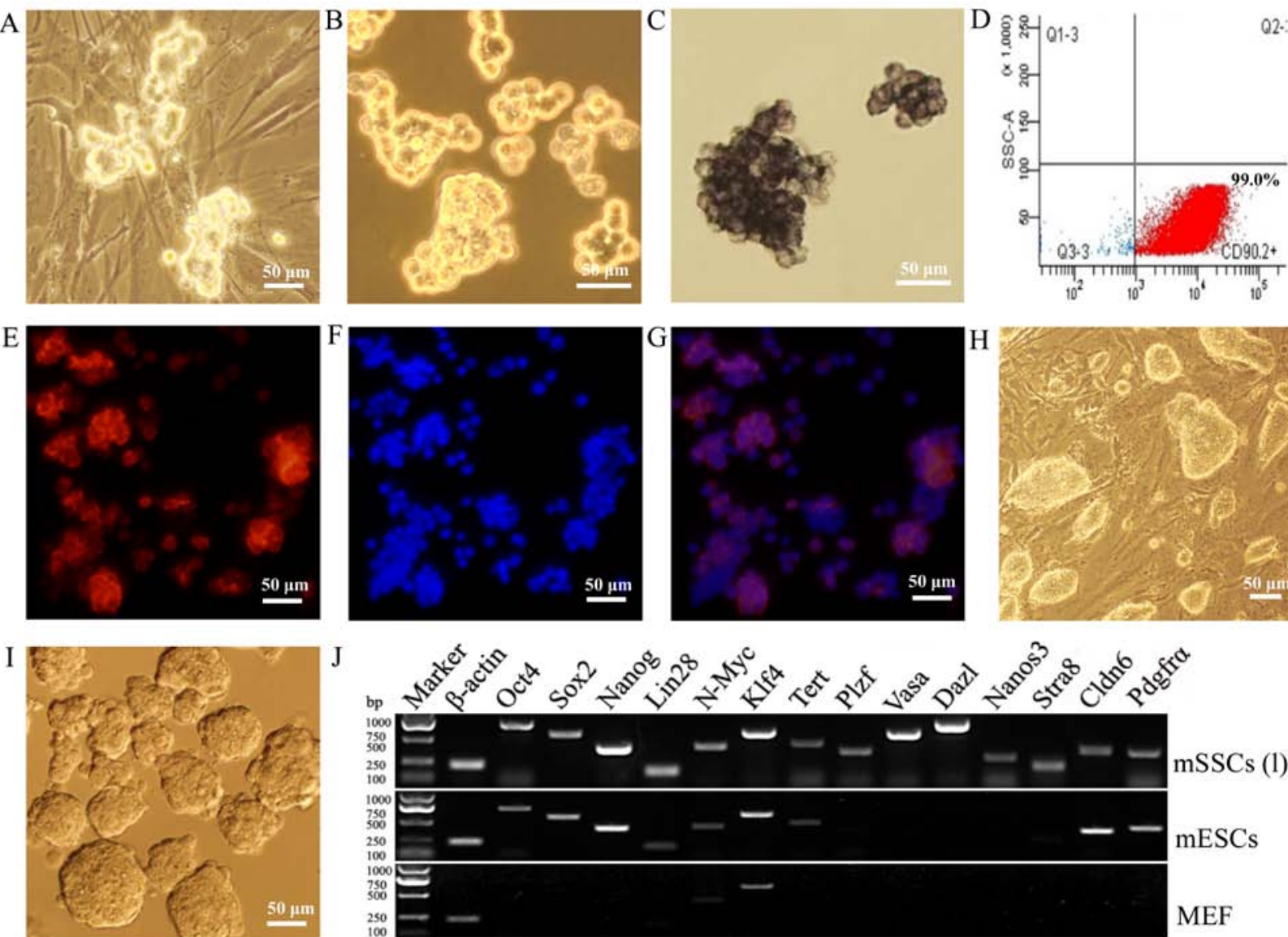

Figure 2. Characterization of long-term propagated mouse spermatogonial stem cells (mSSCs) (1). Representative images of (A) the typical mSSCs (1) colonies on mouse embryonic fibroblast (MEF) feeder cells, (B) the mSSCs (1) colonies without feeder cells, which were used for further analysis, and (C) mSSCs (1) exhibiting alkaline phosphatase (AP staining) activity. (D) Flow cytometric analysis of mSSCs (1) performed using the CD90.2 antibody. Representative images of (E) immunofluorescence staining of GFR $\alpha 1$, (F) Hoechst 33342-stained cell nuclei and (G) merged images of (E and F). Representative images of (H) the colonies of mouse embryonic stem cells (mESCs) cultured on MEF feeder cells and (I) the mESCs colonies without feeder cells, which were used for further analysis. (J) Expression of pluripotency and germ genes was compared in mSSCs (1) and mESCs.
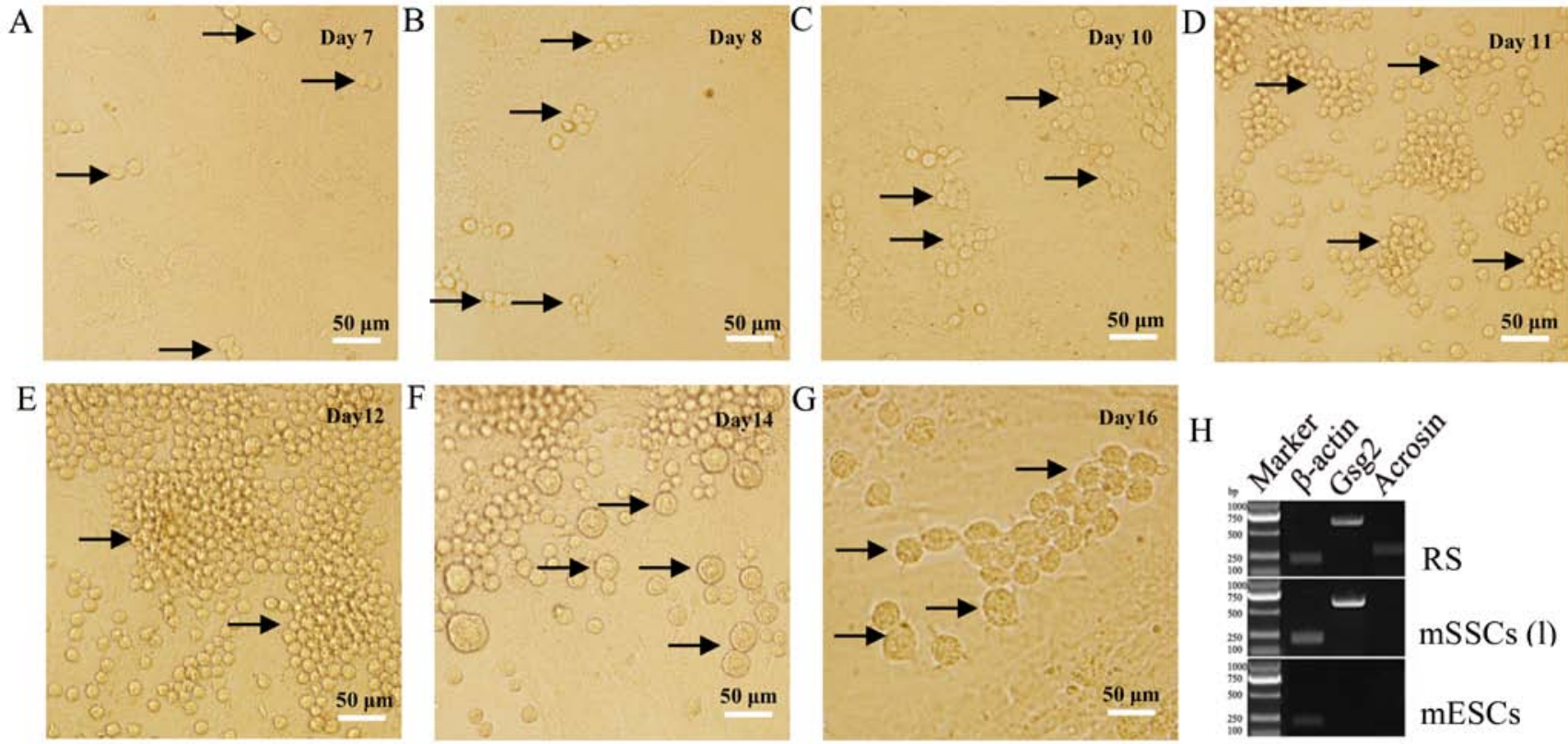

Figure 3. Induction of differentiation of long-term propagated mouse spermatogonial stem cells [mSSCs (1)] into sperms. Representative images showing the following (using black arrows): (A) A-paired (Apr) spermatogonia at day 7, A-aligned (Aal) spermatogonia of (B) 4- (Aal-4) at day 8, (C) 8- (Aal-8) at day 10, (D) and 16- (Aal-16) cells at day 11, and (E) differentiated spermatogonia of A1-A4, intermediate (In) and B spermatogonia at day 12. (F) Bulky cells termed B spermatogonia at day 14. (G) Round spermatids (RSs) appeared with multiple tail cells at day 16. (H) RS exhibited mRNA expression of Gsg2 and Arosin. mESCs, mouse embryonic stem cells. 


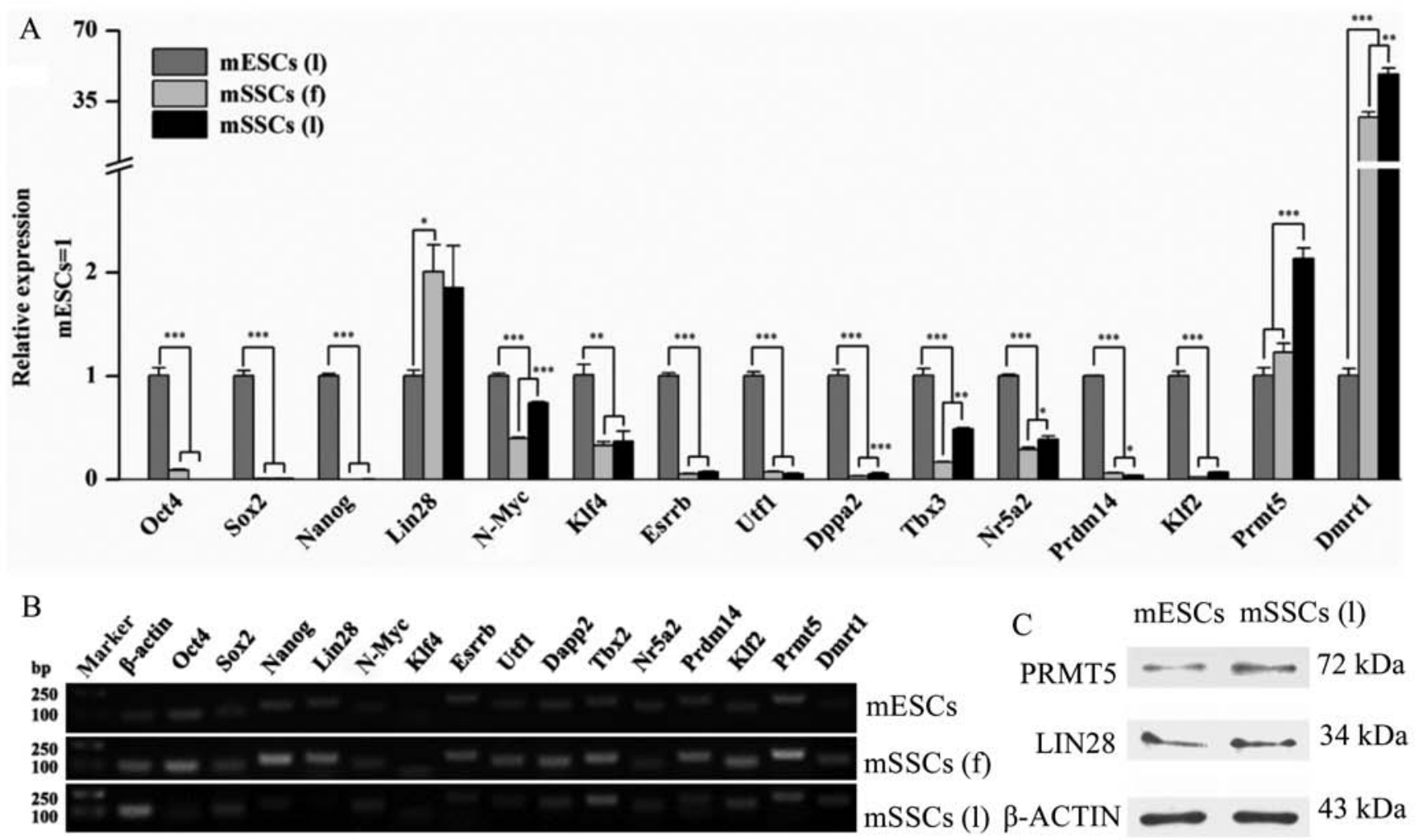

Figure 4. Relative mRNA expression levels of transcription factors in mouse spermatogonial stem cells (mSSCs). (A) Relative mRNA expression of transcription factors in mSSCs is shown, $n=3,{ }^{*} \mathrm{p}<0.05,{ }^{* *} \mathrm{p}<0.01$ and ${ }^{* * *} \mathrm{p}<0.001$. (B) Confirmation of qPCR products of transcription factors. (C) Western blot analysis of PRMT5 and LIN28 in mouse embryonic stem cells (mESCs) and long-term propagated mouse spermatogonial stem cells [mSSCs (1)]. mSSCs (f), freshly isolated mouse spermatogonial stem cells.

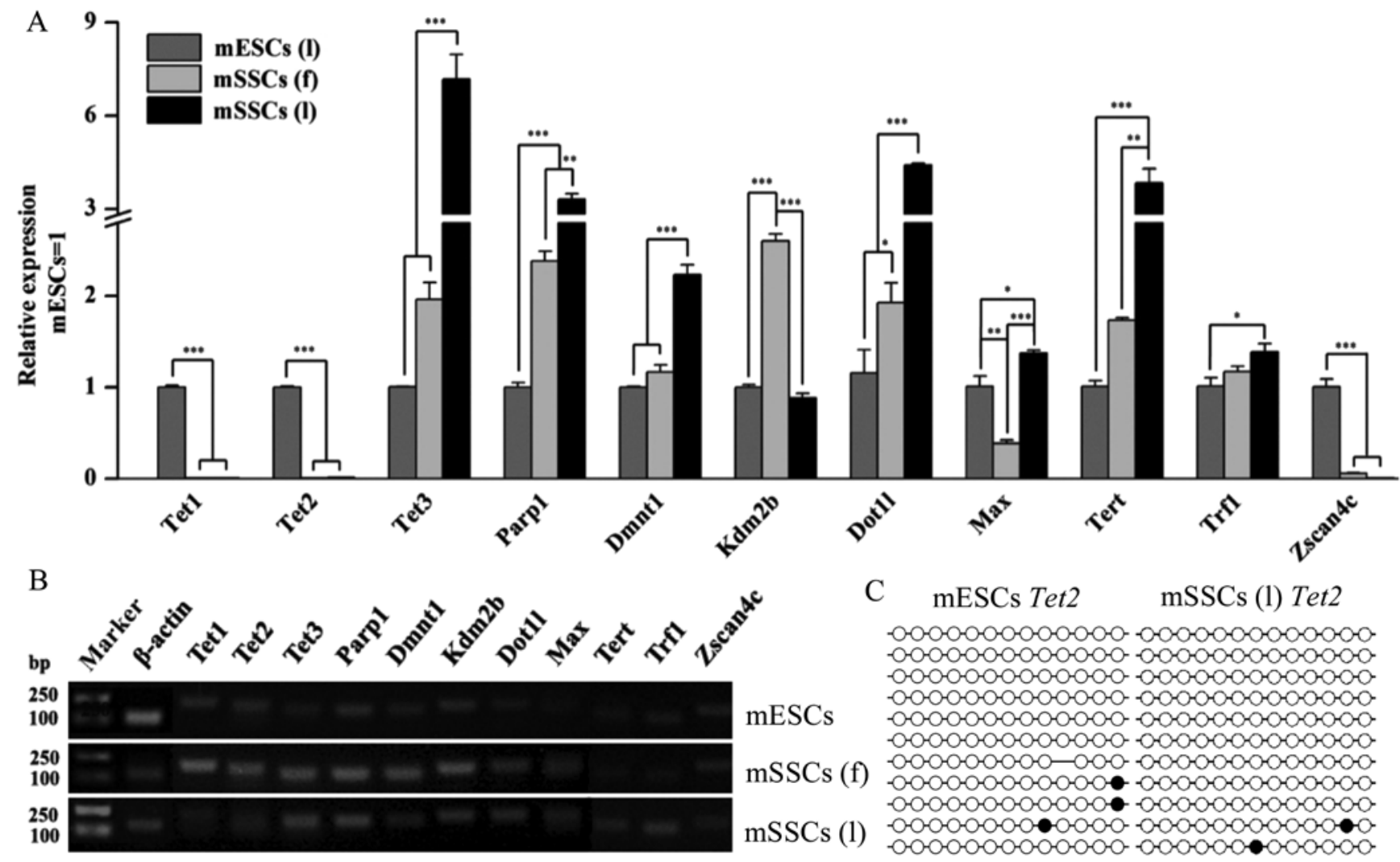

Figure 5. Relative mRNA expression levels of epigenetic factors in mouse spermatogonial stem cells (mSSCs). (A) Relative mRNA expression of epigenetic factors in mSSCs is shown, $n=3,{ }^{*} \mathrm{p}<0.05,{ }^{* *} \mathrm{p}<0.01$ and ${ }^{* * *} \mathrm{p}<0.001$. (B) Confirmation of qPCR products of epigenetic factors. (C) Analysis of methylation levels of the Tet 2 promoter for mouse embryonic stem cells (mESCs) and long-term propagated mouse spermatogonial stem cells [mSSCs (1)]. mSSCs (f), freshly isolated mouse spermatogonial stem cells. 
of mSSCs (13). In addition, the enrichment of mSSCs using CD90.2 microbeads was more efficient than the conventional isolation methods (13). Herein, we observed that the mSSCs (1) exhibited AP activity and expressed the SSC markers, GFR $\alpha 1$ and CD90.2, which is in agreement with previous findings (14). Further experiments demonstrated that the mSSCs (1) expressed germ genes (Plzf, Vasa, Dazl, Nanos3 and Stra 8$)$ and pluripotency genes (Oct4, Sox2, Nanog, Lin28, $N-M y c, K l f 4$ and Tert). Cldn6 has been identified as a novel surface marker for mouse PSCs (15), and Pdgfra was found to be involved in the regulation of cell division and migration (16). Our results showed that Cldn6 and Pdgfro were expressed on the mSSCs (1). The successful establishment of mSSCs is characterized by their self-renewal potential and ability to differentiate into sperm (17). Herein, we showed that the mSSCs (l) were capable of differentiating into sperm, by observing the morphological characteristics of mSSCs (1) as well as by determining the expression of the sperm markers, Gsg2 and Acrosin. Collectively, our results suggested that the mSSCs (f) isolated from 6-day-old ICR mouse testes using CD90.2 microbeads may be cultured long-term and maintain the ability to differentiate into sperm.

On the one hand, pluripotency transcriptional networks have been found to be crucial for controlling ESC pluripotency and for somatic cell reprogramming $(5,18)$. Well-known transcription factors, Oct4, Sox2, Nanog, Lin28, N-Myc and Klf4, have been used to induce pluripotency $(6,19)$. However, recent evidence has suggested that the downstream factors, Esrrb, Utf1, Lin 28 and Dppa2, may also promote iPSC production (20). It has been demonstrated that $T b x 3$ is essential for pluripotency regulation by regulating the expression of Tet 2 , Dnmt3b and Zscan4 (21). Furthermore, high expression of $\mathrm{Nr} 5 \mathrm{a} 2$ [also known as liver receptor homolog-1 (Lrhl)] had the capacity to replace $O c t 4$ to facilitate reprogramming $(22,23)$. In addition, the germline factors (Prdm14, Klf2 and Prmt5) were necessary for primordial germ cell (PGC) specialization and they simultaneously shared the ability to reprogramme PGCs and somatic cells into PSCs $(24,25)$. Our results indicated that the mSSCs (f) and the mSSCs (l) exhibited low expression of most transcription factors (Oct4, Sox2, Nanog, N-Myc, Klf4, Esrrb, Utf1, Dppa2, Tbx3, Nr5a2, Prdm 14 and Klf2) in contrast with the mESCs. However, using RT-qPCR and western blot analysis, we found a very high expression of Prmt 5 and $\operatorname{Lin} 28$ in the mSSCs (l) indicating that they may be critical for supporting mSSC reprogramming in vitro. A previous study has shown that Lin28, an abundant protein in ESCs, may repress let-7 microRNA processing, thereby controlling ESC self-renewal and differentiation (26). Prmt5 may mediate histone methylation and interacted with Stat 3 to stimulate the conversion of the inner cell mass, primordial germ cells, epiblast stem cells, and somatic cells into PSCs $(25,27,28)$. Moreover, it has been demonstrated that the knockdown of Dmrtl facilitated mSSC reprogramming (10). Our results also revealed that Drmtl was expressed at a high level in both types of mSSCs.

On the other hand, epigenetic mechanisms are important for mammalian development and cellular reprogramming (5). The maintenance of particular gene expression patterns has been attributed to DNA methylation and certain histone modifications (5). Epigenetic factors (Tet1, Tet2, Tet3, Parp1, Dnmt1, Kdm2b, Dotll, Max, Tert, Trf1 and Zscan4c) may alter genomic methylation and chromatin structure, which is directly associated with pluripotency and reprogramming (5).

The genomic methylation enzymes, Tet1, Tet2, Tet3, Parpl and Dnmtl, are essential regulators of gene expression and reprogramming. Specifically, Tet 2 and Parpl were found to be required for early-stage epigenetic modifications during somatic cell reprogramming (29). In addition, a recent study found that Tet 3 played a possible role in germ cell modification of the zygotic paternal genome (30). We have shown that Tet 3 and Parpl, genes involved in genomic methylation, were expressed at a higher level in mSSCs (l) compared with the mSSCs (f) and the mESCs; this may be key to mSSC epigenetic reprogramming. Furthermore, it has been demonstrated that Parpl was engaged in the modulation of DNA damage repair and gene transcription, and it promoted epigenetic reprogramming during the early stages of iPSC formation (31). Dnmt1, which was found to be involved in sustaining genomic DNA methylation and regarded as a barrier to iPSC reprogramming (10), exhibited higher expression in the mSSCs than in the mESCs in this study. Notably, we found a significantly lower level of Tet 2 in the mSSCs (1) versus the mESCs, which may play a key role in SSC reprogramming. However, this low expression was not due to DNA methylation of the Tet2 promoter according to our bisulfite sequencing PCR analysis.

Histone-associated modified enzymes (Kdm2b, Dot $1 l$ and Max) may change the structure of chromatin to influence gene expression. It has been demonstrated that $K d m 2 b$ plays a role in anti-senescence and pluripotency and may improve iPSC generation $(32,33)$. A recent study found that histone H3 lysine 79 (H3K79) methytransferase, a crucial epigenetic enzyme for transcriptional regulation, served as a barrier to reprogramming and restrained the expression of Nanog and Lin28 (34). Evidence suggests that Max interacts with histone $\mathrm{H} 3 \mathrm{~K} 9$ methyltransferases and negatively controls germ cell-specific genes in mESCs (35). We found that there were similar expression levels of $K d m 2 b$ and Max in the mSSCs (l) and the mESCs, indicating their potential roles in facilitating SSC reprogramming. However, Dotll was more highly expressed in the mSSCs (l) implying its possible inhibitory effect in SSC reprogramming. In addition, the lower expression of Max in the mSSCs (f) versus the mESCs and the mSSCs (1) may contribute to sustained high levels of germline factor expression for gametogenesis.

Telomere maintenance is essential for chromosome stability, cell replicative capacity, and the induction and establishment of pluripotency $(36,37)$. It has been demonstrated that Tert (38), TrfI (36) and Zscan4c (37) were involved in the modulation of telomere length, thus, markedly improving reprogramming efficiency and iPSC quality (39). We observed the high expression of Tert and Trf1 in the mSSCs (1) and $Z s c a n 4 c$ in the mESCs; this may provide new insights into mSSC reprogramming.

Taken together, our results suggested that the mSSCs exhibited high expression of pluripotency-associated factors ( $\operatorname{Lin} 28$ and Prmt5), as well as the expression of crucial epigenetic factors (Tet3, Parpl, Max, Tert and Trfl) that may promote reprogramming. However, the high expression of Dnmt1, Dmrtl and Dotll, and the low expression of Tet 1 and Tet 2 in mSSCs (1) may be an obstacle for mSSC reprogramming. 


\section{Acknowledgements}

This study was supported by the National Natural Science Foundation of China (nos. 81170623 and 31402072) and by the China Postdoctoral Science Foundation.

\section{References}

1. Pirouz M, Klimke A and Kessel M: The reciprocal relationship between primordial germ cells and pluripotent stem cells. J Mol Med Berl 90: 753-761, 2012.

2. Kim HJ, Lee HJ, Lim JJ, Kwak KH, Kim JS, Kim JH, Han YM, Kim KS and Lee DR: Identification of an intermediate state as spermatogonial stem cells reprogram to multipotent cells. Mol Cells 29: 519-526, 2010.

3. Saitou M, Kagiwada S and Kurimoto K: Epigenetic reprogramming in mouse pre-implantation development and primordial germ cells. Development 139: 15-31, 2012.

4. Gifford CA, Ziller MJ, Gu H, Trapnell C, Donaghey J, Tsankov A, Shalek AK, Kelley DR, Shishkin AA, Issner R, et al: Transcriptional and epigenetic dynamics during specification of human embryonic stem cells. Cell 153: 1149-1163, 2013.

5. Orkin SH and Hochedlinger K: Chromatin connections to pluripotency and cellular reprogramming. Cell 145: 835-850, 2011.

6. Takahashi K and Yamanaka S: Induction of pluripotent stem cells from mouse embryonic and adult fibroblast cultures by defined factors. Cell 126: 663-676, 2006.

7. Onder TT, Kara N, Cherry A, Sinha AU, Zhu N, Bernt KM, Cahan P, Marcarci BO, Unternaehrer J, Gupta PB, et al: Chromatin-modifying enzymes as modulators of reprogramming. Nature 483: 598-602, 2012.

8. Kurosaki H, Kazuki Y, Hiratsuka M,Inoue T, Matsui Y, Wang CC, Kanatsu-Shinohara M, Shinohara T, Toda T and Oshimura M: A comparison study in the proteomic signatures of multipotent germline stem cells, embryonic stem cells, and germline stem cells. Biochem Biophys Res Commun 353: 259-267, 2007.

9. Fujino RS, Ishikawa Y, Tanaka K, Kanatsu-Shinohara M, Tamura K, Kogo H, Shinohara T and Hara T: Capillary morphsxogenesis gene (CMG)-1 is among the genes differentially expressed in mouse male germ line stem cells and embryonic stem cells. Mol Reprod Dev 73: 955-966, 2006.

10. Takashima S, Hirose M, Ogonuki N, Ebisuya M, Inoue K, Kanatsu-Shinohara M, Tanaka T, Nishida E, Ogura A and Shinohara T: Regulation of pluripotency in male germline stem cells by Dmrt1. Genes Dev 27: 1949-1958, 2013.

11. Kubota H, Avarbock MR and Brinster RL: Culture conditions and single growth factors affect fate determination of mouse spermatogonial stem cells. Biol Reprod 71: 722-731, 2004.

12. Hu M, Wei H, Zhang J, Bai Y, Gao F, Li L and Zhang S: Efficient production of chimeric mice from embryonic stem cells injected into 4- to 8-cell and blastocyst embryos. J Anim Sci Biotechnol 4: 12, 2013.

13. Zhang X, Li L, Bai Y, Shi R, Wei H and Zhang S: Mouse undifferentiated spermatogonial stem cells cultured as aggregates under simulated microgravity. Andrologia 46: 1013-1021, 2014.

14. Godmann M, May E and Kimmins S: Epigenetic mechanisms regulate stem cell expressed genes Pou5f1 and Gfral in a male germ cell line. PLoS One 5: e12727, 2010.

15. Wang L, Xue Y, Shen Y, Li W, Cheng Y, Yan X, Shi W, Wang J, Gong Z, Yang G, et al: Claudin 6: A novel surface marker for characterizing mouse pluripotent stem cells. Cell Res 22 : 1082-1085, 2012

16. Eberhart JK, He X, Swartz ME, Yan YL, Song H, Boling TC, Kunerth AK, Walker MB, Kimmel CB and Postlethwait JH: MicroRNA Mirn140 modulates Pdgf signaling during palatogenesis. Nat Genet 40: 290-298, 2008.

17. Ventelä S, Mäkelä JA, Kulmala J, Westermarck J and Toppari J: Identification and regulation of a stage-specific stem cell niche enriched by Nanog-positive spermatogonial stem cells in the mouse testis. Stem Cells 30: 1008-1020, 2012.

18. Kim J, Chu J, Shen X, Wang J and Orkin SH: An extended transcriptional network for pluripotency of embryonic stem cells. Cell 132: 1049-1061, 2008

19. Yu J, Vodyanik MA, Smuga-Otto K, Antosiewicz-Bourget J, Frane JL, Tian S, Nie J, Jonsdottir GA, Ruotti V, Stewart R, et al: Induced pluripotent stem cell lines derived from human somatic cells. Science 318: 1917-1920, 2007.
20. Buganim Y, Faddah DA, Cheng AW, Itskovich E, Markoulaki S, Ganz K, Klemm SL, van Oudenaarden A and Jaenisch R: Single-cell expression analyses during cellular reprogramming reveal an early stochastic and a late hierarchic phase. Cell 150 1209-1222, 2012

21. Han J, Yuan P, Yang H, Zhang J, Soh BS, Li P, Lim SL, Cao S, Tay J, Orlov YL, et al: Tbx3 improves the germ-line competency of induced pluripotent stem cells. Nature 463: 1096-1100, 2010.

22. Tay YM, Tam WL, Ang YS, Gaughwin PM, Yang H, Wang W, Liu R, George J, Ng HH, Perera RJ, et al: MicroRNA-134 modulates the differentiation of mouse embryonic stem cells, where it causes post-transcriptional attenuation of Nanog and LRH1. Stem Cells 26: 17-29, 2008.

23. Heng JC1, Feng B, Han J, Jiang J, Kraus P, Ng JH, Orlov YL, Huss M, Yang L, Lufkin T, et al: The nuclear receptor Nr5a2 can replace Oct4 in the reprogramming of murine somatic cells to pluripotent cells. Cell Stem Cell 6: 167-174, 2010.

24. Gillich A, Bao S, Grabole N, Hayashi K, Trotter MW, Pasque V, Magnúsdóttir E and Surani MA: Epiblast stem cell-based system reveals reprogramming synergy of germline factors. Cell Stem Cell 10: 425-439, 2012.

25. Nagamatsu G, Kosaka T, Kawasumi M, Kinoshita T, Takubo K, Akiyama H, Sudo T, Kobayashi T, Oya M and Suda T: A germ cell-specific gene, Prmt5, works in somatic cell reprogramming. J Biol Chem 286: 10641-10648, 2011.

26. Zhong X, Li N, Liang S, Huang Q, Coukos G and Zhang L: Identification of microRNAs regulating reprogramming factor LIN28 in embryonic stem cells and cancer cells. J Biol Chem 285: 41961-41971, 2010.

27. Yang J, van Oosten AL, Theunissen TW, Guo G, Silva JC and Smith A: Stat 3 activation is limiting for reprogramming to ground state pluripotency. Cell Stem Cell 7: 319-328, 2010.

28. Tee WW, Pardo M, Theunissen TW, Yu L, Choudhary JS, Hajkova P and Surani MA: Prmt5 is essential for early mouse development and acts in the cytoplasm to maintain ES cell pluripotency. Genes Dev 24: 2772-2777, 2010.

29. Doege CA, Inoue K, Yamashita T, Rhee DB, Travis S, Fujita R, Guarnieri P, Bhagat G, Vanti WB, Shih A, et al: Early-stage epigenetic modification during somatic cell reprogramming by Parp1 and Tet2. Nature 488: 652-655, 2012.

30. Deplus R, Delatte B, Schwinn MK, Defrance M, Méndez J, Murphy N, Dawson MA, Volkmar M, Putmans P, Calonne E, et al: TET2 and TET3 regulate GlcNAcylation and H3K4 methylation through OGT and SET1/COMPASS. EMBO J 32: 645-655, 2013.

31. Villani P, Fresegna AM, Ranaldi R, Eleuteri P, Paris L, Pacchierotti F and Cordelli E: X-ray induced DNA damage and repair in germ cells of PARP1(-/-) male mice. Int J Mol Sci 14: 18078-18092, 2013.

32. Liang G, He J and Zhang Y: Kdm2b promotes induced pluripotent stem cell generation by facilitating gene activation early in reprogramming. Nat Cell Biol 14: 457-466, 2012.

33. He J, Shen L, Wan M, Taranova O, Wu H and Zhang Y: Kdm2b maintains murine embryonic stem cell status by recruiting PRC1 complex to $\mathrm{CpG}$ islands of developmental genes. Nat Cell Biol 15: 373-384, 2013.

34. Chen J, Liu H, Liu J, Qi J, Wei B, Yang J, Liang H, Chen Y, Chen J, Wu Y, et al: H3K9 methylation is a barrier during somatic cell reprogramming into iPSCs. Nat Genet 45: 34-42, 2013.

35. Maeda I, Okamura D, Tokitake Y, Ikeda M, Kawaguchi H, Mise N, Abe K, Noce T, Okuda A and Matsui Y: Max is a repressor of germ cell-related gene expression in mouse embryonic stem cells. Nat Commun 4: 1754, 2013.

36. Schneider RP, Garrobo I, Foronda M, Palacios JA, Marión RM, Flores I, Ortega S and Blasco MA: TRF1 is a stem cell marker and is essential for the generation of induced pluripotent stem cells. Nat Commun 4: 1946, 2013.

37. Zalzman M, Falco G, Sharova LV, Nishiyama A, Thomas M, Lee SL, Stagg CA, Hoang HG, Yang HT, Indig FE, et al: Zscan4 regulates telomere elongation and genomic stability in ES cells. Nature 464: 858-863, 2010

38. Winkler T, Hong SG, Decker JE, Morgan MJ, Wu C, Hughes WM, Yang Y, Wangsa D, Padilla-Nash HM, Ried T, et al: Defective telomere elongation and hematopoiesis from telomerase-mutant aplastic anemia iPSCs. J Clin Invest 123: 1952-1963, 2013.

39. Jiang J, Lv W, Ye X, Wang L, Zhang M, Yang H, Okuka M, Zhou C, Zhang X, Liu L and Li J: Zscan4 promotes genomic stability during reprogramming and dramatically improves the quality of iPS cells as demonstrated by tetraploid complementation. Cell Res 23: 92-106, 2013. 